\title{
EMBRYOGENIC CALLUS INDUCTION AND REGENERATION IN ANTHER CULTURE OF NOUG (GUIZOTIA ABYSSINICA (L.F) CASS.)
}

\author{
Misteru Tesfaye ${ }^{1}$, Tileye Feyissa ${ }^{2}$ and Likyelesh Gugsa ${ }^{1}$ \\ ${ }^{1}$ Holetta Research Centre, Ethiopian Institute of Agricultural Research, PO Box 31, \\ Holetta, Ethiopia. E-mail: mtesfayew@yahoo.com \\ ${ }^{2}$ Faculty of Life Sciences, Addis Ababa University, PO Box 1176, Addis Ababa, Ethiopia
}

\begin{abstract}
Two released noug varieties, Shambu and Fogera, were used for this experiment. Initially, two experiments were conducted to identify the appropriate morphological stage of capitula (buds) for harvesting maximum number of responsive anthers and to study the optimum cold pretreatment duration for callus induction from the anthers. Three culture media, MS, B5 and $\mathrm{NN}$, were employed for callus induction. MS medium, with nine different combinations of KN and IAA, was used for shoot regeneration study. Three different concentrations of IBA and growth regulator-free MS medium were used for the rooting experiment. The results showed that capitula, fully or slightly covered by sepal having whitish-green or greenish-yellow anthers, were the optimum stages of harvesting capitula; callus was efficiently induced when the capitula were pretreated at $4^{\circ} \mathrm{C}$ for 24 hours. The types of calli induced significantly $(\mathrm{P} \leq 0.05)$ varied among the three media. Embryogenic calli were mainly produced in $\mathrm{NN}_{\mathrm{N}}$ and $\mathrm{B}_{5}$ media, while varying in texture and colour. High percentage of embryogenic calli $(80 \%)$ was induced on NN medium from the variety Shambu, followed by $\mathrm{B}_{5}$ medium showing $40 \%$ inductions for both varieties. Among nine different $\mathrm{KN}$ and IAA combinations, $2 \mathrm{mg} / 1 \mathrm{KN}$ combined with $1 \mathrm{mg} / 1 \mathrm{IAA}$, was the most efficient for shoot regeneration. It was also found that $0.5 \mathrm{mg} / 1 \mathrm{IBA}$ was optimum for root induction. In the growth room as well as in the glasshouse, the survival rate of regenerants was generally better for the variety Shambu than for Fogera.
\end{abstract}

\section{Key words/ phrases: Anther culture, embryogenic callus, Guizotia abyssinica (L.f) Cass, regeneration}

\section{INTRODUCTION}

Noug (Guizotia abyssinica (L.f) Cass.) is an oil seed indigenous to Ethiopia, where the crop is a major source of edible oil. Noug oil is used not only for consumption but also for industrial purposes in the preparation of soaps, paints, illuminants and lubricants, and for cleaning machinery (Riley and Hiruy Belayneh, 1989). The press-cake left over after oil extraction is an excellent poultry and livestock feed (Seegler, 1983). Despite its considerable importance, noug has low seed yield due to several factors such as seed shattering, lodging, non-synchronized maturity of heads and self-incompatibility.

The out-crossing and self-incompatibility nature of noug pose serious difficulty for inbred line development, and make breeding efforts difficult. Studying anther culture of noug is beneficial for in vitro haploid plant production, which in turn can be used as a better alternative method for inbred line development within a short period of time. Such lines can also be used to improve the selection efficiency of quantitative characters by incorporating them in recurrent selection cycle or used in development of synthetic cultivar of noug populations with desirable traits.

In noug, callus induction and subsequent shoot regeneration from anthers was first reported by Sarvesh et al. (1993), and later androclonal variation of regenerants were studied by Sarvesh et al. (1994). According to these studies, both embryogenic and non-embryogenic calli were induced on three different basal media (MS, $\mathrm{B}_{5}$, and $\mathrm{N}_{6}$ ) containing different combinations and concentrations of 2, 4-D, NAA and KN.

This success of anther culture, however, has so far been limited to Indian genotypes, and the anther culture response is genotype and environment dependent (Swapan, 2005). Therefore, the objective of the present study was to develop in vitro culture techniques for embryogenic callus 
induction and regeneration from anther cultures of two improved high yielding Ethiopian noug varieties, Shambu and Fogera. Since induction of callus from anther depends on stages of buds from which the anther explants are excised and the duration of cold pretreatment (Sandra, 1996), this study also attempted to determine the optimum morphological stages of harvesting capitula and the duration of cold pretreatment of the explant source flower heads.

Abbreviations: $\mathrm{B}_{5}$, Gamborg medium; BAP, 6Benzylaminopurine; 2, 4-D, 2, 4-dichlorophenoxy acetic acid; IBA, indole butyric acid; KN, kinetin; LS, Linsmaier and Skoog medium; MS, Murashige and Skoog medium; $\mathrm{N}_{6}$, Chu medium; NAA, naphtalene acetic acid; NN, Nitsch and Nitsch; PGR, plant growth regulator.

\section{MATERIALS AND METHODS}

\section{Plant materials}

Two released noug varieties, Shambu and Fogera, obtained from highland oil crops research division of Holetta Agricultural Research Centre (Ethiopia), were used in this study. The anther donor plants were raised in pots containing red soil, compost and sand at a ratio of 3:2:1, respectively. Then, the seedlings were allowed to grow in a glasshouse at Holetta Agricultural Research Centre, at an average temperature of $25 \pm 2^{\circ} \mathrm{C}$ under natural light conditions.

\section{Morphological staging of capitula (buds)}

Morphological staging system of capitula (buds) was undertaken in order to determine the appropriate stage of capitula for maximum number of responsive anthers can be isolated. Capitula (buds) of the variety Shambu were categorized into four stages based on the extent of opening of the sepals and emergence of petals within the flower heads. Four samples of buds replicated three times were used to investigate each stage of buds. The capitula diameter of each stage was determined using interval scale. Finally, the state of disc floret at each stage was characterized in terms of bud diameter, floret and anther colour at three different positions (i.e., centre, medium and outer) of the capitula.

\section{Cold-pretreatment}

Six immature buds were taken from the $1^{\text {st }}$ and $2^{\text {nd }}$ stages of capitula to study the effect of cold pre-treatment on the induction of callus from the anthers of the variety Shambu. The immature flower buds were pre-treated at $4^{\circ} \mathrm{C}$ for different durations of 0 (control), 12, 24, 36 and 48 hours. Ten anthers from each of the pre-treated flower buds were cultured in Petri dishes containing MS basal media supplemented with $2 \mathrm{mg} / 1$ 2, 4-D and $0.3 \mathrm{mg} / 1 \mathrm{KN}$ in three replications. To assess the comparative effects of cold pre-treatment, anthers from the flower buds without cold pretreatment (control) were also cultured in the same way. The frequency of responsive anthers was assessed in terms of callus induction percentage.

\section{Induction of callus under different basal media}

After cold-pretreatment using the optimum time duration (24 hours), anthers of the varieties Shambu and Fogera taken from Stage 1 capitula , were cultured on three different culture media, MS (Murashige and Skoog, 1962), B (Gamborg et al., 1968) and NN (Nitsch and Nitsch, 1969). The basal media contained $2 \%$ sucrose, all supplemented with $2 \mathrm{mg} / 1 \mathrm{NAA}$ plus $0.3 \mathrm{mg} / 1 \mathrm{KN}$ and solidified with $0.8 \%$ agar. Ten anthers of the varieties Shambu and Fogera were separately cultured in Petri dishes containing $25 \mathrm{ml}$ of the above basal media each replicated four times. All cultures were maintained in moist chamber under 16 hours light (2000 lux fluorescent intensity) and 8 hours dark cycle at $22 \pm 2^{\circ} \mathrm{C}$. Data on the number of callus formed in each Petri dish were recorded every week. Finally the callus induction for each variety was expressed as a percentage of the number of anthers plated.

\section{Shoot regeneration}

To evaluate the effects of different concentrations and combinations of plant growth regulators for shoot regeneration, embryogenic calli of the variety Shambu derived from MS medium supplemented with $2 \mathrm{mg} / 1$ 2, 4-D and $0.3 \mathrm{mg} / 1$ KN were transferred onto MS-regeneration media supplemented with three levels $(1,2,3 \mathrm{mg} / \mathrm{l})$ of 
$\mathrm{KN}$ each either alone or in combination with two levels $(0.5$ and $1 \mathrm{mg} / \mathrm{l})$ of IAA. A jar with a single callus, measuring approximately $2-3 \mathrm{~mm}$ in diameter, was a unit of replication and there were twelve replications for each treatment. The cultures were incubated at $22 \pm 2^{\circ} \mathrm{C}$ with 16 hours photoperiod and 2000 lux fluorescent intensity in moist chamber. Cultures with shoots were expressed as a percentage.

\section{Rooting of shoots}

Rooting of shoot regenerants of Shambu and Fogera varieties was assessed using MS rooting media, supplemented with three $(0.5,1.0,2.0$ $\mathrm{mg} / \mathrm{l}$ ) concentrations of IBA and a control without IBA. A culture with a single shoot was used as a unit of replication and there were 4 replications for each treatment. This experiment was repeated three times for each treatment. The cultures were maintained in moist chamber with 16 hours photoperiod at $22 \pm 2^{\circ} \mathrm{C}$ and light intensity of 2000 lux. After three weeks, the percentage of cultures with roots and the numbers of roots produced per shoot were recorded every three days.

\section{Acclimatization and plantlet growing in the glasshouse}

About 5 to $8 \mathrm{~cm}$ tall plantlets with well developed roots of 2 to $3 \mathrm{~cm}$ length and 2 to 3 leaves were removed from the culture jars using forceps and transferred into pots. The pots were filled with red soil, compost and sand in the ratio of 3:2:1, respectively. For acclimatization, each pot was covered with plastic bag and kept in the growth room at 22 to $25 \pm 2^{\circ} \mathrm{C}$ with photoperiod of 16 hours and light intensity of 2000 lux. After two weeks, pots were transferred to the glasshouse, the plastic bag gradually removed, and regenerants were grown to maturity. The survival rate of the plantlets of Shambu and Fogera varieties was evaluated by counting the number of plants that were alive or dead four weeks after transfer into pots.

\section{Experimental design and data analysis}

All culture experiments were laid out in completely randomized design (CRD). Data were analyzed using SAS computer software (Version, 1998). The mean separation method (LSD) was used to compare means between treatments.

\section{RESULTS AND DISCUSSION}

\section{Identification of the appropriate harvesting stage of capitula (buds)}

The extents of opening of sepal and petal emergence were used as external morphological tools for grouping capitula into four stages (Table 1). Determination of capitula (buds) stage is very important since it facilitates the capture of the best responsive anthers. Based on this study, disc florets taken from capitula stages 1 and 2 were found to be the ones with maximum number of responsive anthers. However, the responsiveness of anthers at these stages varied with the position of florets. Florets of stage 1 capitula at the centre position were very small, too young and had sticky anthers. Those of stage 2 at the outer position (near the sepal) were old enough with some pollen released and, thus, were nonresponsive at these positions. It was observed that stages 3 and 4 of capitula were the ones with the least number of responsive anthers, since the majority of the disc floret at these stages contained matured anthers that release pollen. Such anthers are usually considered as too old for androgenesis. In general, florets that are found at medium and outer side positions of stage 1 capitula and those found at the centre and medium positions of stage 2 capitula, were the most appropriate florets with maximum number of responsive anthers. It was also observed that the best responsive anthers in these florets could be identified by their light-green or greenishyellow colour (Table 1). Sarvesh et al. (1993) also found that capitula, containing anthers with light-green colour, was best responsive for callus induction in Indian noug. 


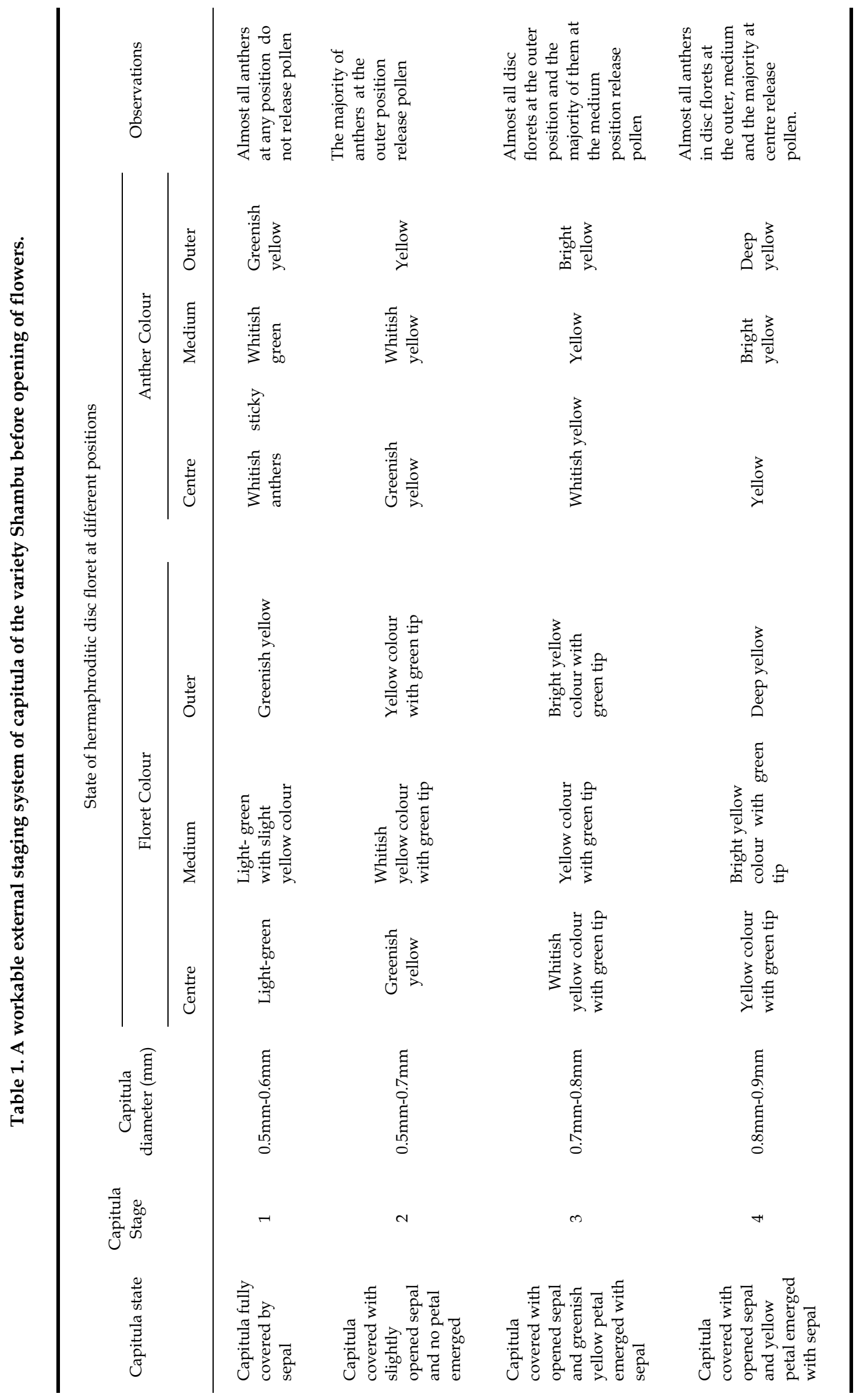




\section{Optimization of cold pre-treatment duration}

In studying the effects of cold pre-treatment on callus induction from anther culture of the variety Shambu, the least callus induction percentage was obtained from anthers taken from capitula without cold-pretreatment (Table 2). Often, cold pre-treatment at $4^{\circ} \mathrm{C}$ has been used in anther culture of many plant species to promote androgenesis (Yamagunchi et al., 1990); however, the duration of cold pre-treatment has to be optimized for each plant species. On the basis of the findings in the present study, capitula of stages 1 and 2 were used to investigate the effects for cold-pretreatment at $4^{\circ} \mathrm{C}$ for five different durations of 0 (control), 12, 24, 36 and 48 hours. The control was direct culturing without cold pre-treatment. As it is indicated in Table 2, callus induction percentage increased by $43 \%$ when capitula were pre-treated for 12 hours. The highest callus induction percentages, $70 \%$ and $77 \%$, were obtained from stages 1 and 2 capitula, respectively, pre-treated for 24 hours. In the second best cold pre-treatment duration (36 hours), the same percentage of callus induction $(60 \%)$ was obtained for both stages. The callus induction percentages of anthers taken from 48 hours pre-treated capitula were $12 \%$ (for stage 1 ) and $13 \%$ (for stage 2). Based on this specific investigation, the best cold pre-treatment duration of capitula (buds) for better induction of callus in anther culture of the variety Shambu was 24 hours although it was not significantly $(p \leq 0.05)$ different from 12 and 36 hours (Table 2). This result is consistent with the cold pre-treatment duration applied in anther culture of Indian genotypes (Sarvesh et al., 1993).

\section{Nature of induced callus under different basal media}

Based on visual observation, two distinct kinds of calli, embryogenic and non-embryogenic, were recognized in the three callus induction media (MS, B 5 and NN). Sarvesh et al. (1993) also obtained the same results, although they used $\mathrm{N}_{6}$ instead of NN. Usually embryogenic calli are characterized by globular-shaped embryo with compact morphology, whereas non-embryogenic calli are commonly distinguished by their large and amorphous morphology (Liang et al., 1987). In this study, embryogenic and non-embryogenic calli observed in anther culture of noug depended on the type of media used. MS media supplemented with $2 \mathrm{mg} / 1 \mathrm{NAA}$ in combination with $0.3 \mathrm{mg} / 1 \mathrm{KN}$ produced predominantly nonembryogenic calli identified by friable texture and large amorphous morphology (Fig. 1A). But it also induced embryogenic calli (Fig. 1B). The other two media (NN and $\mathrm{B}_{5}$ ), supplemented with the same plant growth regulator combination produced embryogenic calli that differed in external appearance between the two basal media. Embryogenic callus with shiny and smooth texture, and light-green colour was observed on NN medium (Fig. 1C) while compact and rough textured calli with reddish-yellow colour were noted on $\mathrm{B}_{5}$ medium (Fig. 1D).

Percentages of calli of each embryogenic and non-embryogenic type also varied significantly $(\mathrm{P} \leq 0.05)$ among the three media (Table 3$)$. The maximum percentage of non-embryogenic calli $(100 \%)$ was obtained on MS medium from anthers of the variety Fogera. This medium also induced $80 \%$ non-embryogenic calli from anthers of the variety Shambu. High percentage of embryogenic calli $(80 \%)$ was produced on NN medium from anthers of Shambu followed by $B_{5}$ medium $(40 \%)$.

Table 2. Effect of different cold-pretreatment $\left(4^{\circ} \mathrm{C}\right)$ on callus induction in anthers of the variety Shambu.

\begin{tabular}{ccc}
\hline $\begin{array}{c}\text { Pretreatment duration } \\
\text { (hours) }\end{array}$ & \multicolumn{2}{c}{$\begin{array}{c}\text { Induction } \\
\text { percentages }\end{array}$} \\
\cline { 2 - 3 } & Stage 1 & Stage 2 \\
\hline 0 & $10.00^{\mathrm{c}}$ & $16.67^{\mathrm{c}}$ \\
12 & $53.33^{\mathrm{ab}}$ & $56.67^{\mathrm{ab}}$ \\
24 & $70.00^{\mathrm{a}}$ & $76.67^{\mathrm{a}}$ \\
36 & $60.00^{\mathrm{ab}}$ & $60.00^{\mathrm{ab}}$ \\
48 & $40.00^{\mathrm{b}}$ & $43.33^{\mathrm{bc}}$ \\
\hline
\end{tabular}

Mean values with the same letter are not significantly different at $\mathrm{P} \leq 0.05$ (LSD).

Table 3. Percentage of embryogenic and nonembryogenic calli in anther culture of varieties Shambu and Fogera.

\begin{tabular}{|c|c|c|c|c|}
\hline \multirow[t]{2}{*}{ Media } & \multicolumn{2}{|c|}{$\begin{array}{c}\text { Embryogenic } \\
\text { calli }(\%)\end{array}$} & \multicolumn{2}{|c|}{$\begin{array}{c}\text { Non-embryogenic } \\
\text { calli }(\%)\end{array}$} \\
\hline & Shambu & Fogera & Shambu & Fogera \\
\hline MS & $20^{a}$ & $0^{a}$ & $80^{a}$ & $100^{a}$ \\
\hline $\mathrm{B}_{5}$ & $40^{\mathrm{b}}$ & $40^{\mathrm{b}}$ & $60^{b}$ & $60^{\mathrm{b}}$ \\
\hline NN & $80^{c}$ & $60^{c}$ & $20^{c}$ & $40^{c}$ \\
\hline
\end{tabular}

Mean values with the same letter are not significantly different at $\mathrm{P} \leq 0.05$ (LSD). 


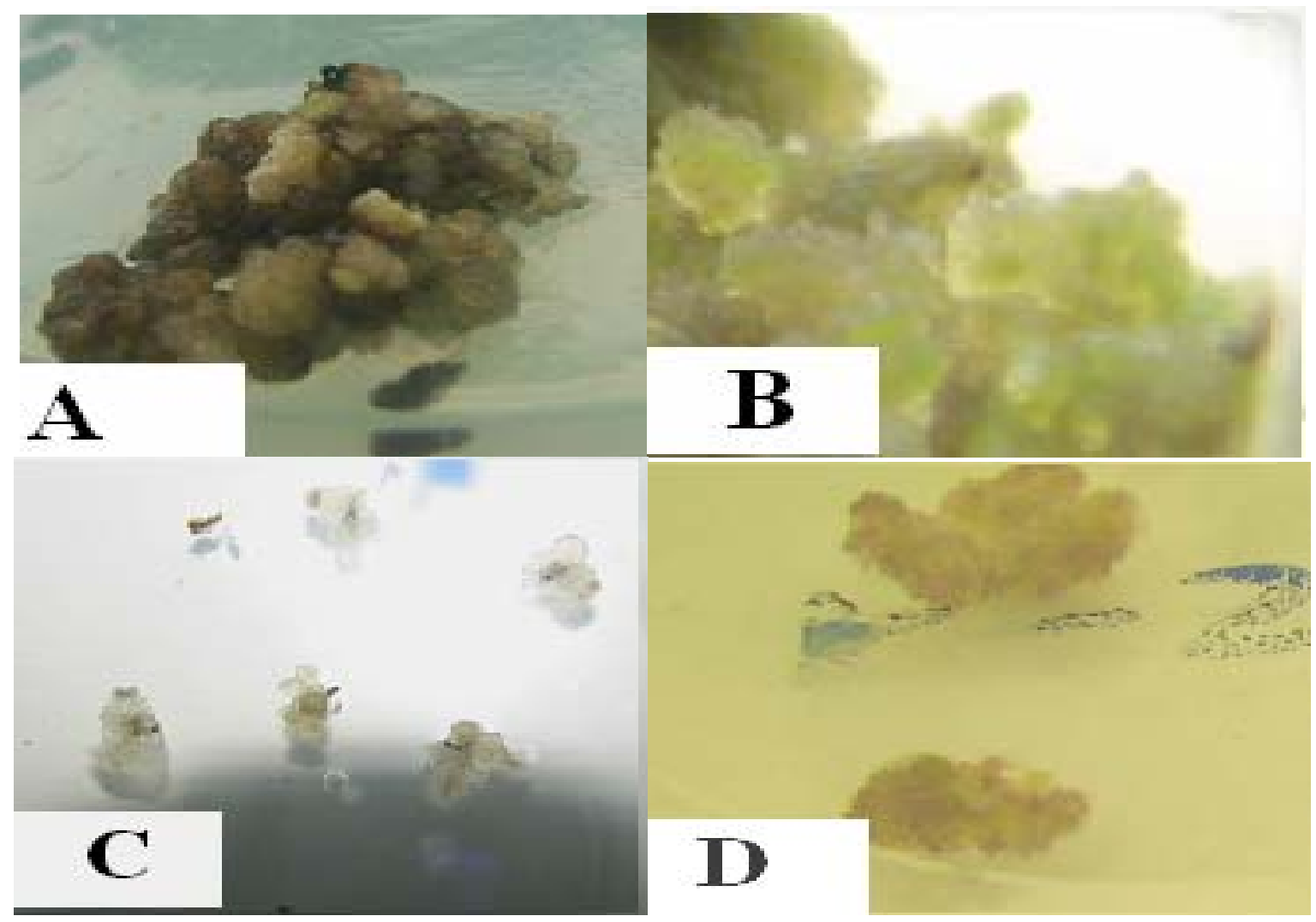

Fig. 1. Types of calli induced from anthers of Shambu in three different media (MS, NN and $B_{5}$ ) supplemented with 2 mg/l NAA in combination with $0.3 \mathrm{mg} / \mathrm{l} \mathrm{KN}$. (A) Non-embryogenic callus on MS medium after four weeks of the initial culture, (B) Embryogenic callus on MS medium four weeks after the initial culture, (C) Embryogenic callus induced on NN medium just two weeks after culture and (D) Embryogenic callus induced on $B_{5}$ medium after three weeks of the initial culture.

Effects of plant growth regulators on shoot regeneration

The response of induced calli for shoot regeneration at different combinations and concentrations of kinetin and Indole acetic acid (IAA) in anther culture of the variety Shambu are presented in Table 4 . About $26 \%$ of the total 108 calli transferred to MS regeneration media produced shoots at all levels of $\mathrm{KN}$ and IAA combinations. Percentage of cultures with shoots ranged from zero to $83 \%$; thus, considerable variations in shoot regeneration existed among the different growth regulators tested. Calli from the variety Shambu failed to regenerate shoots at $1 \mathrm{mg} / 1 \mathrm{KN}$ alone while calli began to regenerate at $1 \mathrm{mg} / 1$ concentration of $\mathrm{KN}$ when $0.5 \mathrm{mg} / 1$ of IAA was added to the regeneration media. Equal percentage of shoot regeneration (25\%) was obtained in media supplemented with $1 \mathrm{mg} / \mathrm{l} \mathrm{KN}$ in combination with $0.5 \mathrm{mg} / 1$ IAA, and also with $3 \mathrm{mg} / 1 \mathrm{kN}$ alone. Similarly, there was no variation in shoot regeneration percentage between culture media that contained $3 \mathrm{mg} / 1 \mathrm{KN}$ in combination with either 0.5 and $1 \mathrm{mg} / 1$ IAA. Regeneration medium supplemented with 2 $\mathrm{mg} / 1 \mathrm{KN}$ combined with IAA (0.5 and $1 \mathrm{mg} / \mathrm{l})$ gave better shoot regeneration percentage. Regeneration medium with $2 \mathrm{mg} / 1 \mathrm{KN}$ in combination with $1 \mathrm{mg} / 1 \mathrm{IAA}$, however, produced maximum shoot regeneration percentage $(83 \%)$ as compared to regeneration medium with 2 $\mathrm{mg} / 1 \mathrm{KN}$ in combination with $0.5 \mathrm{mg} / 1 \mathrm{IAA}(42 \%)$. Thus, MS medium with $2 \mathrm{mg} / \mathrm{l} \mathrm{KN}$ in combination with $1 \mathrm{mg} / 1 \mathrm{IAA}$ was the most efficient growth regulator combination for shoot regeneration in anther culture of noug, particularly for the variety Shambu. 
Table 4. Percentage of shoot regeneration of calli in anther culture of the variety Shambu at different combinations and concentrations of kinetin and IAA from $\mathrm{N}=12$ calli inoculated for each treatment.

\begin{tabular}{crrr}
\hline Treatments & $\begin{array}{c}\text { Growth } \\
\text { regulators (mg/l) }\end{array}$ & $\begin{array}{c}\text { No of cultures } \\
\text { with shoots }\end{array}$ & $\begin{array}{c}\text { Percentage of } \\
\text { cultures with shoots }\end{array}$ \\
\hline A & $1.0 \mathrm{KN}$ & 0 & 0 \\
B & $1.0 \mathrm{KN}+0.5 \mathrm{IAA}$ & 1 & 8.3 \\
$\mathrm{C}$ & $1.0 \mathrm{KN}+1.0 \mathrm{IAA}$ & 3 & 25 \\
$\mathrm{D}$ & $2.0 \mathrm{KN}$ & 2 & 16.7 \\
E & $2.0 \mathrm{KN}+0.5 \mathrm{IAA}$ & 5 & 41.7 \\
F & $2.0 \mathrm{KN}+1.0 \mathrm{IAA}$ & 10 & 83.3 \\
G & $2.0 \mathrm{KN}$ & 3 & 25 \\
H & $3.0 \mathrm{KN}+0.5 \mathrm{IAA}$ & 2 & 16.7 \\
I & $3.0 \mathrm{KN}+1.0 \mathrm{IAA}$ & 2 & 16.7 \\
\cline { 3 - 4 } & & & Total = 28 \\
\end{tabular}

According to Nabors et al. (1983), non-embryogenic calli are not regenerable. Similarly, the non-embryogenic calli in this study failed to regenerate when transferred to the MS regeneration medium. The regenerated shoots were from embryogenic calli of $\mathrm{NN}_{\mathrm{N}}$ and $\mathrm{B}_{5}$ rather than from embryogenic calli of MS. Regenerated shoots of various treatments of regeneration media are presented in Figure 2. The response of the different combinations and concentrations of $\mathrm{KN}$ and IAA differed not only in the percentage of shoot formation but also in the quality of shoots they produced. Poor quality shoots, with weak standing ability or with very thin stalk, were produced in cultures with low concentrations of KN (1 $\mathrm{mg} / \mathrm{l})$ and with higher concentration of $\mathrm{KN}(3$ $\mathrm{mg} / \mathrm{l}$ ) combined with 0.5 or $1.0 \mathrm{mg} / 1$ IAA (Fig. 2A and 2B). Good quality shoot regenerants, with better vigour and even branched stems, were obtained in cultures supplemented with the intermediate concentration of $\mathrm{KN}(2 \mathrm{mg} / \mathrm{l})$, either alone or in combination with 0.5 or $1.0 \mathrm{mg} / 1$ IAA (Fig. 2C and 2D).

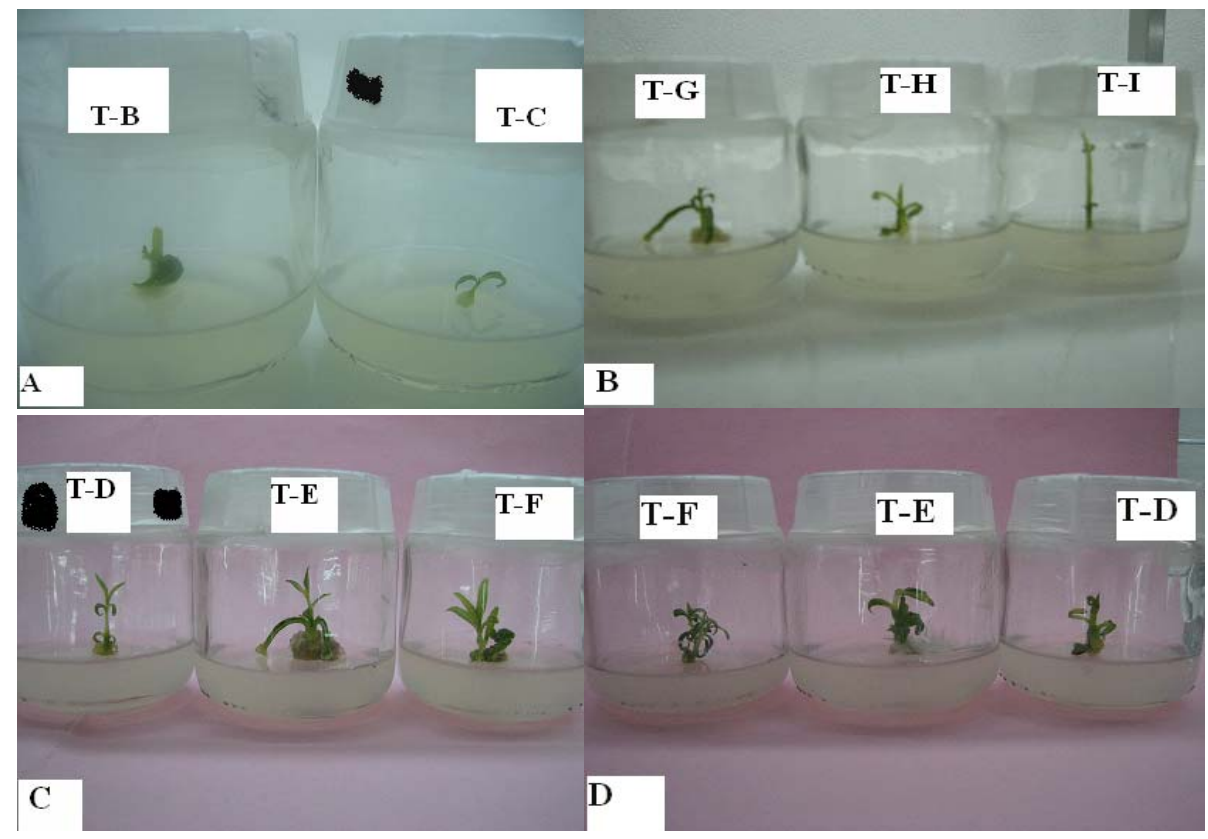

Fig. 2. Shoots regenerated under different $\mathrm{KN}$ and IAA concentration and combination in anther culture of the variety Shambu. (A) and (B) shoots from calli of low regeneration potential observed in media supplemented with $1 \mathrm{mg} / 1 \mathrm{KN}$ in combination with $0.5 \mathrm{mg} / 1 \mathrm{IAA}$ (T-B) and with $1 \mathrm{mg} / 1 \mathrm{KN}$ in combination with $0.5 \mathrm{mg} / 1 \mathrm{IAA}$ (T-C), respectively. (C) and (D) Shoots from calli of good regeneration potential observed in media supplemented with $2 \mathrm{mg} / 1 \mathrm{KN}$ alone or in combination with $0.5 \mathrm{and} 1.0 \mathrm{mg} / 1$ IAA. Note: T-B, T-C, T-D, T-E T-F, T-G, T-H, and T-I refer to treatments that are assigned in Table 4. 


\section{Effects of IBA concentration for rooting}

For shoot regenerants of the variety Shambu, the first three IBA concentrations $(0,0.5,1 \mathrm{mg} / \mathrm{l})$ significantly differed from the maximum IBA concentration $(2 \mathrm{mg} / \mathrm{l})$ in terms of average number of roots formed (Table 5). In case of the variety Fogera, there were significant variations $(\mathrm{P} \leq 0.05)$ in average number of roots among the different concentrations of IBA such as between IBA concentration of $0.5 \mathrm{mg} / 1$ and $1 \mathrm{mg} / \mathrm{l}$, and between the control and the maximum IBA concentration $(2 \mathrm{mg} / \mathrm{l})$. Although shoots from the two varieties were able to form roots in all IBA concentrations, there was variation in percentage of rooting for shoots from the variety Fogera. In the variety Fogera, the rooting media with IBA concentrations of 1 and $2 \mathrm{mg} / 1$ scored 50 and 25 rooting percentage, respectively (Table 5 ). In general, MS-rooting medium with $0.5 \mathrm{mg} / 1 \mathrm{IBA}$ was the optimum concentration for rooting of shoots in both varieties, since this medium not only showed $100 \%$ rooting but also produced the maximum average number of roots (Table 5). Roots produced for shoots of Shambu and Fogera are presented in Figure 3. In contrast to the present findings, Sarvesh et al. (1993) reported that MS media without PGR to be the best rooting media for Indian niger genotypes.

Table 5. Number and percentage of roots that emerged during culturing of regenerated shoots of Shambu and Fogera in MS rooting media, supplemented with different concentration of IBA.

\begin{tabular}{lrrr}
\hline Variety & $\begin{array}{c}\text { IBA } \\
(\mathrm{mg} / \mathrm{l})\end{array}$ & $\begin{array}{r}\text { Number of } \\
\text { Root/Shoot }\end{array}$ & $\begin{array}{c}\text { Rooting } \\
\text { percentage }\end{array}$ \\
\hline Shambu & 0 & $8.5 \pm 1.3^{\mathrm{a}}$ & 100 \\
& 0.5 & $11.0 \pm 1.8^{\mathrm{a}}$ & 100 \\
& 1.0 & $9.5 \pm 1.3^{\mathrm{a}}$ & 100 \\
& 2.0 & $3.5 \pm 1.3^{\mathrm{b}}$ & 100 \\
Fogera & 0 & $7.5 \pm 1.3^{\mathrm{a}}$ & 100 \\
& 0.5 & $8.5 \pm 1.3^{\mathrm{ab}}$ & 100 \\
& 1.0 & $3.8 \pm 4.3^{\mathrm{ac}}$ & 50 \\
& 2.0 & $0.5 \pm 1.0^{\mathrm{c}}$ & 25 \\
\hline
\end{tabular}

Mean values in a column with different letters are significantly different $(\mathrm{p}<0.05)$ as judged by LSD.

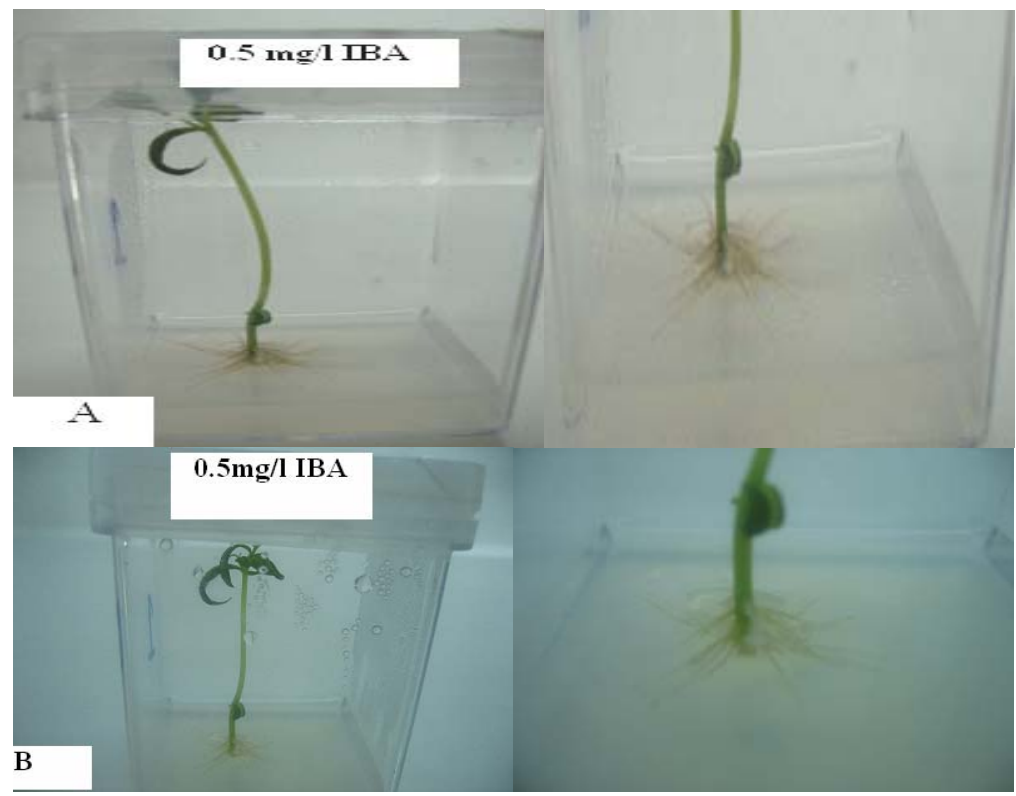

Fig. 3. Root formation on MS-rooting medium supplemented with $0.5 \mathrm{mg} / \mathrm{l}$ of IBA, incubated in moist chamber under 16 hours light (2000lux fluorescent intensity) and 8 hours dark cycle at $22^{\circ} \mathrm{C} \pm 2^{\circ} \mathrm{C}$. (A) Roots formed from shoots of Fogera and (B) Roots formed from shoots of Shambu. 


\section{Acclimatization and survival rate}

Sixteen regenerants from the variety Shambu and eleven regenerants from the variety Fogera were successfully transferred into pots and taken into the growth room covered with plastic for acclimatization (Table 6). However, 6 of the regenerants of each variety failed to survive in the growth room. The remaining 10 regenerants from each variety continued growing in the growth room for two weeks and were then taken to a glasshouse for further growth. In the glasshouse, 4 regenerants of the variety Shambu and 3 regnerants of that of Fogera wilted and died. Thus, only 6 regenerants of variety Shambu and 2 regenerants of the variety Fogera remained in the glasshouse (Table 6). The survival rate of regenerants of the variety Shambu seemed to be better than that of the variety Fogera since more plantlets of Shambu survived both in the growth room and in the glasshouse. Regenerants of the varieties Shambu and Fogera that survived in the growth room and eventually in the glasshouse are shown in Figure 4.

During the present study of noug, it was possible to produce complete plants through culturing anthers of noug. Overall, the present findings demonstrated successful callus induction and subsequent regeneration from anther cultures of two Ethiopian noug varieties, thereby indicating that the procedure can be developed into an in vitro haploid plant production technique which in turn facilitates the breeding program on the crop that has hitherto been challenged by the out-crossing and self-incompatibility nature of the crop.

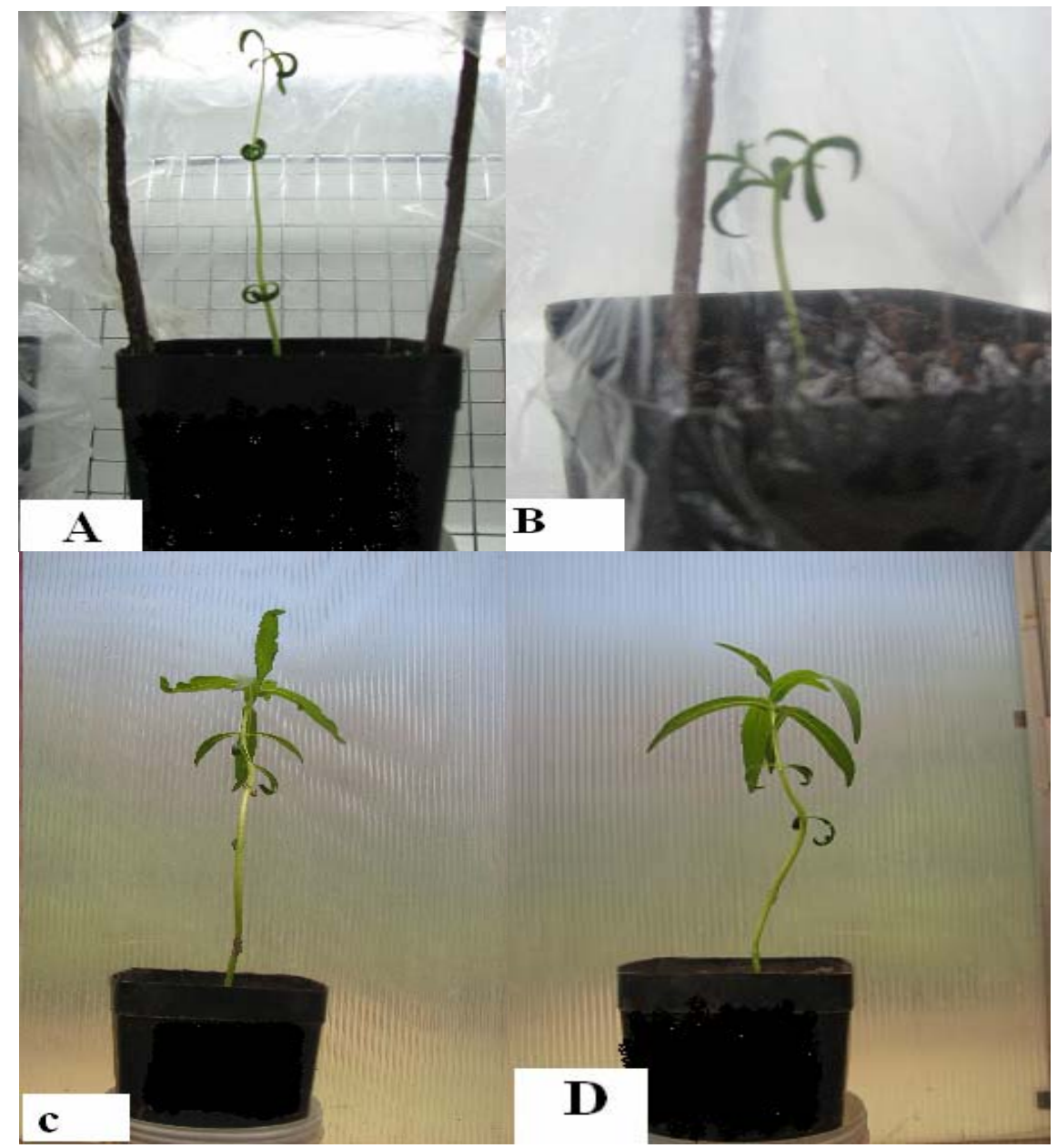

Fig. 4. Regenerants of Shambu (A) and Fogera (B), in growth room, acclimatized under 16 hours light (2000lux) and 8 hours dark cycle and a temperature of $22^{\circ} \mathrm{C}-25^{\circ} \mathrm{C} \pm 2^{\circ} \mathrm{C}$. Regenerants of Shambu (C) and Fogera (D )in glasshouse grown at a temperature of $25^{\circ} \mathrm{C} \pm 2^{\circ} \mathrm{C}$ and under natural light. 
Table 6. Regenerants status under growth room [16 hours light (2000 lux) and 8 hours dark cycle] and glasshouse (under natural light and at average temperature of $25^{\circ} \mathrm{C} \pm 2{ }^{\circ} \mathrm{C}$ ) conditions.

\begin{tabular}{|c|c|c|c|c|c|}
\hline \multirow[b]{2}{*}{ Varieties } & \multicolumn{5}{|c|}{ Regenerants status } \\
\hline & $\begin{array}{l}\text { No of plantlets } \\
\text { transferred } \\
\text { into pots }\end{array}$ & $\begin{array}{l}\text { No of regenerants } \\
\text { that died in growth } \\
\text { room }\end{array}$ & $\begin{array}{l}\text { No of regenerants } \\
\text { that survived in } \\
\text { growth room }\end{array}$ & $\begin{array}{c}\text { No of regenerants } \\
\text { that died in } \\
\text { glasshouse }\end{array}$ & $\begin{array}{c}\text { No of regenerants } \\
\text { that survived in } \\
\text { glasshouse }\end{array}$ \\
\hline Shambu & 16 & 6 & 10 & 4 & 6 \\
\hline Fogera & 11 & 6 & 5 & 3 & 2 \\
\hline Total & 27 & 12 & 15 & 7 & 8 \\
\hline
\end{tabular}

\section{ACKNOWLEDGMENTS}

The first author (MT) is very grateful to the Department of Biology, Addis Ababa University, for its continuous support in advisory and field logistics. The authors strongly acknowledge the Ethiopian Institute of Agricultural Research in general, and the Plant Biotechnology Department of Holetta Agricultural Research Centre in particular, for their support in the accomplishment of the experiment by providing seeds and laboratory facilities.

\section{REFERENCES}

1. Gamborg, O.L., Miller, R.A. and Ojima, K. (1968). Nutrient requirements of suspension cultures of soyabean root cells. Exp. Cell Res. 50:151158.

2. Liang, G.H., Xu, A. and Tang, H. (1987). Direct Generation of Wheat Haploids via Anther Culture . Crop. Sci. 27:336-339.

3. Murashige, T. and Skoog, F. (1962). A revised medium for rapid growth and bioassay with tobacco tissue culture. Physiol. Plant 15:473497.

4. Nabors, M.W., Heyser, J.W., Dykes, T.A. and DeMott, K.J. (1983). Long duration, high frequency plant regeneration from cereals tissue culture. Planta. 157:385-391.

5. Nitsch, J.P. and Nitsch, C. (1969). Haploid plants from pollen grains. Science 163:85-87.
6. Riley, K.W. and Hiruy Belayneh (1989). Their breeding and utilization, Niger. In: Oil Crops of the World, pp. 394-403, (Robbelen, G., Doweny, R.K. and Ashri, A., eds). Mc Graw Hill Publishing Company, New York.

7. Sandra, M.R. (1996). Haploid cultures. In: Plant Tissue Culture Concepts and Laboratory Exercises, pp. 241-246, (Robert, N.T. and Dennis, J.G, eds). CRC Press, Boca Raton, New York, London and Tokyo.

8. Sarvesh, A., Reddy, T.P. and Kishor, B.B. (1993). Embryogenesis and organogenesis in culture anthers of an oil yielding crop niger (Guizotia abyssinica. Cass). Plant Cell Tiss. Org. Cult. 35:75-80.

9. Sarvesh, A., Reddy, T.P. and Kishor, B.B. (1994). Androclonal variation in niger (Guizotia abysssinica Cass). Euphytica. 79:59-64.

10. Seegler, C.J.P. (1983). Oil Plants in Ethiopia. Their Taxonomy and Agricultural Significance. Centre for Agricultural Publication and Documentation, PUDOC, Wageningen, pp. 122-146.

11. Swapan, K.D. (2005). Androgenic haploids: Factors controlling development and its application in crop improvemenet. Current Science 89:1870-1878.

12. Yamagunchi, M., Yomoda, A. and Hinata, K. (1990). Varietal difference in the response to low temperature for callus formation in anther culture of rice. Jpn. J. Breed. 40:193-198. 